\section{S70 EFFECTIVENESS OF DIFFERENT PARAMETERS AT ADMISSION AS PROGNOSTIC MARKERS FOR MORTALITY DUE TO SARS-COV-2: A 2-CENTRE EXPERIENCE IN UK AND SPAIN}

${ }^{1} M E$ Shuvo, ${ }^{2} M$ Schwiening, ${ }^{3} F$ Soares, ${ }^{4} R$ Thompson, ${ }^{2} O$ Feng, ${ }^{2} R J$ Samworth, ${ }^{2}$ NW Morrell, ${ }^{2} \mathrm{SJ}$ Marciniak, ${ }^{1} \mathrm{~W}$ Thomas, ${ }^{2} \mathrm{E}$ Soon. ${ }^{1}$ Cambridge University Hospitals NHS Trust, Cambridge, UK; ${ }^{2}$ University of Cambridge, Cambridge, UK; ${ }^{3}$ Universidade Federal do Rio Grande do Sul, Rio Grande do Sul, Brazil; ${ }^{4}$ University of Sheffield, Sheffield, UK

\subsection{6/thorax-2021-BTSabstracts.76}

Rationale SARS-CoV-2 is an international health crisis that has overwhelmed the healthcare capacity of many countries. There is a need for a simple and easily usable biomarker to assist in making urgent clinical decisions.

Objectives We sought to find and validate a simple, easily measurable, dependable single-parameter biomarker to predict mortality in swab-positive SARS-CoV-2 patients.

Methods All swab-positive patients were recruited from Cambridge University Hospitals NHS Trust between March-July 2020 (inclusive) to form the Cambridge cohort. All swab-positive patients were recruited from the HM Hospitales group of hospitals from March-April 2020 to form the Spanish cohort. Details of clinical parameters and potential biomarkers were extracted from the electronic patient records. Data was deidentified prior to access.

Measurements and Main Results There were 522 patients in the Cambridge cohort and 1,643 in the Spanish cohort, with a mean age of $64.6 \pm 20.9$ and $66.8 \pm 15.8$ years, respectively. Age, CRP, D-dimer, urea, troponin, NT-proBNP, IL-6 and ISARIC scores were significantly raised in the non-survivors versus survivors for the Cambridge cohort $(P<0.0001$ for all). The two cohorts were analysed independently using Receiver Operating Curves and compared to a previously validated multi-component score (ISARIC). For the Cambridge cohort, troponin and NTproBNP levels proved to be the most effective single parameters at predicting mortality, with an area under curve (AUC, 95\% confidence interval) of $0.7680(0.7098-0.8263)$ and 0.7360 (0.6724-0.7991) respectively, $P<0.0001$ for both. The AUC for ISARIC (an 8-component score) was 0.8069 ( $\mathrm{P}<0.0001$ ). Interestingly the AUCs for CRP and D-dimer were not as high as would be expected (0.6141 [0.5534-0.6747] and 0.6808 [0.6178-0.7438] respectively, figure 1). A similar pattern is seen in the Spanish cohort, with troponin (AUC of 0.800 [0.7728-0.8276]) outperforming CRP and D-dimer (0.6858 [0.6525-0.7192] and 0.6979 [0.6605-0.7352], respectively).

\section{ROC mortality}
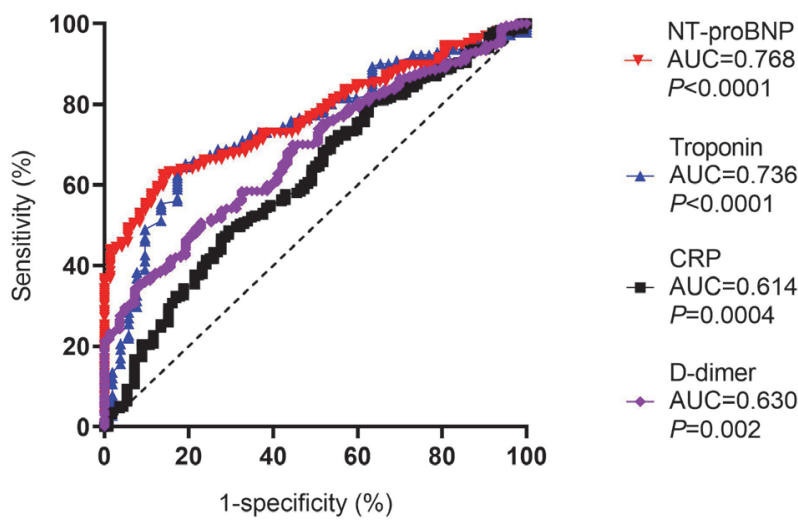

Abstract S70 Figure 1 ROCs for parameters with 30-day mortality as outcome
Conclusions The cardiac biomarkers troponin and NT-proBNP proved to be the best single-parameter biomarkers for predicting mortality in the Cambridge cohort, and this was borne out in the Spanish cohort.

\section{S71 A RETROSPECTIVE ANALYSIS OF ROX SCORE FOR PREDICTING TREATMENT FAILURE AND PROGRESSION TO INVASIVE VENTILATION IN COVID PATIENTS REQUIRING ENHANCED RESPIRATORY SUPPORT}

DJ Ritchie, S Fairbairn. Aneurin Bevan University Health Board, Cwmbran, UK

\subsection{6/thorax-2021-BTSabstracts.77}

Introduction Due to the rapid escalation of demand for critical care during the COVID19 pandemic there was an increasing requirement for systems that predicted patients requirement of invasive respiratory support. While more complex prediction models have been proposed (Douville et al. 2021 BJA 123:3 578- 589), we analysed the validity of the existing ROX score test, in patients presenting with severe COVID19 respiratory disease.

Method We retrospectively utilised data for COVID HDU admissions in a single UK hospital during a fixed period from Nov 2020 to Feb 2021. The ROX score was calculated at 2 , 6, 12 and $24 \mathrm{hr}$ for patients started on either CPAP or HFNO and who were candidates for full escalation to critical care in the event of deterioration. ROX score pass (>4.87), fail $(<3.85)$ or indeterminate $(3.85-4.87)$ was decided using the original values determined by Roca et al (2016 JCC 35; 200 205), this was then used to determine the relative risk of intubation (ROI) for patients with low ROX score during their first 24 hrs on enhanced respiratory support.

Results - Of the 233 patients in our dataset, 49 met our inclusion criteria; 28 on HFNO and 21 on CPAP.

\begin{tabular}{|c|c|c|c|c|}
\hline & \multicolumn{2}{|c|}{$\mathrm{ROX}<3.85$} & \multicolumn{2}{|c|}{ ROX3.85-4.87 } \\
\hline & ROI & $\mathrm{RR}$ & ROI & $\mathrm{RR}$ \\
\hline CPAP & $87.5 \%$ & $\begin{array}{l}7(95 \% \mathrm{Cl} 1.1-44.6 \\
\text { P0.019) }\end{array}$ & $66.6 \%$ & $\begin{array}{l}5.33(95 \% \mathrm{Cl} 0.78- \\
36.3 \mathrm{P} 0.043)\end{array}$ \\
\hline HFNO & $87.5 \%$ & $\begin{array}{l}9.63(95 \% \mathrm{Cl} 1.45- \\
63.92 \mathrm{P} 0.009)\end{array}$ & $33.3 \%$ & $\begin{array}{l}3.66(95 \% \mathrm{Cl} 0.48- \\
29.48 \mathrm{P} 0.11)\end{array}$ \\
\hline
\end{tabular}

Conclusion Our study suggests ROX score is valid in predicting intubation in COVID patients requiring enhanced respiratory support. Given the small sample size, further research utilising data from multiple sites would be useful to corroborate findings

\section{S72 LUNG FUNCTION OUTCOMES IN CHILDREN WITH PAEDIATRIC INFLAMMATORY MULTISYSTEM SYNDROME - TEMPORALLY ASSOCIATED WITH SARS- COV-2 (PIMS-TS)}

${ }^{1} \mathrm{M}$ Riley, ${ }^{1} \mathrm{C}$ Doughty, ${ }^{2,3} \mathrm{R}$ Brugha. ${ }^{1}$ Respiratory Physiology, Great Ormond Street Hospital, London, UK; ${ }^{2}$ Paediatric Respiratory Medicine, Great Ormond Street Hospital, London, UK ${ }^{3}$ Infection, Immunity and Inflammation, UCL Great Ormond Street Institute of Child Health London, UK

10.1136/thorax-2021-BTSabstracts.78 
Introduction In March-April 2020, and again in winter '2021 , children began presenting to our centre with a novel systemic inflammatory syndrome associated with SARS-CoV-2 exposure or infection. A group of these children required respiratory support. We present updated data on lung function outcomes following discharge. Data in a subset of individuals in this group has previously been reported (Penner et al, Lancet Child Adolesc Health 2021).

Methods Children with PIMS-TS requiring invasive, or noninvasive, ventilatory support during the acute phase undertook spirometry, body plethysmography and a measurement of transfer factor at a structured follow up 6-weeks post discharge. Data was collected prospectively between April 2020 and February 2021 and are reported as descriptive statistics, with predicted values reported in comparison to Global Lung Initiative data where available.

Results 30 lung function measurements (in 29 patients) were included (table 1). Spirometry was performed at all visits with 1 child unable to achieve a result fulfilling ATS/ERS criteria, and was normal in all other children. 1/27 child (4\%) showed evidence of abnormal alveolar volume and gas exchange efficiency.

Conclusion Similar to other systemic inflammatory syndromes (Staphylococcal toxic shock, Kawasaki disease), and unlike Covid-19 in adults, it appears that children's lungs are at low risk of long term damage by PIMS-TS. This data is preliminary and we have not assessed exercise tolerance, or outcomes in those with presentations that did not require initial respiratory support. Assessments are ongoing in this cohort and in children presenting following infection with new variants of concern.

Abstract S72 Table 1 Table of lung function results expressed as mean and $95 \% \mathrm{Cl}=$ Confidence Interval

\begin{tabular}{|c|c|c|c|}
\hline Demographic & $N=$ & Mean & $(95 \% \mathrm{Cl})$ \\
\hline Age (years) & $\mathrm{N}=30$ & 11.73 & $(10.70,12.77)$ \\
\hline Sex, Female $\%$ & $\mathrm{~N}=14(48 \%)$ & & \\
\hline Height (cm) & $\mathrm{N}=30$ & 152.24 & $(145.62,158.86)$ \\
\hline $\mathrm{Fe}_{\mathrm{NO}}(\mathrm{ppb})$ & $\mathrm{N}=26$ & 16.28 & $(9.01,23.55)$ \\
\hline $\mathrm{FEV}_{1} \%_{\text {pred }}(\%)$ & $\mathrm{N}=29$ & 103.85 & $(98.04,109.66)$ \\
\hline FEV $_{1}$ z-score & $N=29$ & 0.32 & $(0.00,1.00)$ \\
\hline FVC $\%_{\text {pred }}(\%)$ & $\mathrm{N}=29$ & 103.3 & $(98.25,108.35)$ \\
\hline FVC z-score & $N=29$ & 0.25 & $(-0.15,0.66)$ \\
\hline FEV1:FVC & $N=29$ & 98.84 & $(96.69,100.99)$ \\
\hline \multicolumn{4}{|l|}{ Ratio $\%$ pred $(\%)$} \\
\hline FEV1:FVC & $\mathrm{N}=29$ & -0.09 & $(-0.41,0.23)$ \\
\hline \multicolumn{4}{|l|}{ Ratio z-score } \\
\hline $\mathrm{TL}_{\mathrm{CO}} \%$ pred & $N=23$ & 86.69 & $(80.00,93.39)$ \\
\hline $\mathrm{TL}_{\mathrm{co}} \mathrm{z}$-score & $\mathrm{N}=23$ & -1.04 & $(-1.70,-0.37)$ \\
\hline $\mathrm{K}_{\mathrm{CO}} \%_{\text {pred }}$ & $\mathrm{N}=23$ & 97.22 & $(91.34,103.01)$ \\
\hline $\mathrm{K}_{\mathrm{co}} \mathrm{z}$-score & $N=23$ & -0.22 & $(-0.65,0.21)$ \\
\hline VA $\%_{\text {pred }}$ & $\mathrm{N}=23$ & 88.87 & $(84.09,93.65)$ \\
\hline VA z-score & $\mathrm{N}=23$ & -1.01 & $(-1.44,-0.58)$ \\
\hline $\mathrm{FRC}_{\text {pleth }} \%$ pred $(\%)$ & $N=15$ & 88.00 & $(80.99,95.01)$ \\
\hline $\mathrm{FRC}_{\text {pleth }} \mathrm{z}$-score & $\mathrm{N}=15$ & -0.77 & $(-1.26,-0.28)$ \\
\hline TLC $\%_{\text {pred }}(\%)$ & $\mathrm{N}=15$ & 98.2 & $(92.17,104.23)$ \\
\hline TLC z-score & $N=15$ & -0.15 & $(-0.66,0.36)$ \\
\hline RV $\%_{\text {pred }}(\%)$ & $\mathrm{N}=15$ & 83.47 & $(71.34,95.60)$ \\
\hline RV z-score & $\mathrm{N}=15$ & -0.43 & $(-0.88,0.02)$ \\
\hline
\end{tabular}

\section{REFERENCE}

1. Penner, et al. 6-month multidisciplinary follow-up and outcomes of patients with paediatric inflammatory multisystem syndrome (PIMS-TS) at a UK tertiary paediatric hospital: a retrospective cohort study. Lancet Child Adolesc Health 2021;5 (7):473-482.

\section{A cut above: an update in thoracic surgery}

\section{S73 MANAGEMENT OF BRONCHIAL STENOSIS IN POST LUNG TRANSPLANTATION - INITIAL EVALUATION OF BIODEGRADABLE STENTS}

S Cyclewala, M Nardini, A Padukone, N Asadi. Royal Brompton and Harefield Hospital, London, UK

\subsection{6/thorax-2021-BTSabstracts.79}

Introduction Bronchial stenosis one of the most common airway complications post lung transplantation. The incidence varies from about 5 to 20 , most commonly seen between 2 to 9 months post transplantation and is a significant cause of morbidity and mortality.

Methods Retrospective analysis of prospectively collected data of patients who have undergone lung transplantation at the institute over the last 10 years. Patients who have had bronchial stenosis post operatively were identified which was identified on surveillance/diagnostic bronchoscopy. Data was gathered with regards to the type of interventions used to treat the bronchial stenosis and the treatment outcomes were compared, along with looking at the efficacy of absorbable bio degradable stents.

Results A total of 524 lung transplantations were performed, which included bilateral single sequential, single and heart lung transplantation. 44 Patients developed bronchial stenosis out of which 32 patients required interventions for the stenosis. The most common site for non-anastomotic stenosis was found to be bronchus intermedius (28 patients $63 \%$ ) followed by left main bronchus (9 patients - 20\%), right main bronchus $(5-11 \%)$ and left upper lobe bronchus (2\%). The patients were treated in a stepwise approach, initially balloon dilatation (32 patients - 72\%), which was followed up with cryotherapy (15 patients-34\%) and ultimately treated with endobronchial stents ( 9 patients - 18\%).

Currently 4 Patients have undergone biodegradable stent placements ( 2 unilaterally and 1 bilateral) which show better short-term outcomes as compared to metallic stents.

With metallic stents, 3 patients have had an incidence of bronchomalacia, 1 required restenting, and 2 had persistent stenting post removal.

The biodegradable stents have had no reports of bronchomalacia and also decreased the need for intervention to removal the stent.

Conclusions Biodegradable stents have been newly introduced which hold strength initially and degrade over months. It also bypasses the issue of stent removal. Biodegradable stents also show improved FEV1 post bronchial stenosis. Overall biodegradable stents show a promising outcome, although long term follow up and prospective studies need to be undertaken to adequately compare benefits and subsequent complications as compared to conventional stents. 